\title{
EDUCAÇÃO AMBIENTAL: A CONTRIBUIÇÃO DOS PROJETOS ESCOLARES NAS DISCUSSÕESAMBIENTAIS NAS ESCOLAS PÚBLICAS MUNICIPAIS DE COLOMBO/PR
}

\section{Environmental Education: the contribution of schools projects on environmental discussions at Municipal Public Schools of ColombolPR}

\author{
Maria Alice de Oliveira COLLERE ${ }^{1}$
}

\begin{abstract}
RESUMO
As questões ambientais têm ocupado grande espaço nas discussões educacionais, sejam elas formais ou informais, $e$ a Educação Ambiental tem sido defendida como um dos meios capazes de gerar reflexões e ações que levam a novas posturas diante da realidade socioambiental. Instigada a desvendar como se sustentam as ações dos professores em relação às suas práticas ambientais, essa pesquisa buscou analisar os projetos de Educação Ambiental desenvolvidos nas escolas da rede pública municipal, localizadas em Colombo/PR. A presente pesquisa teve por objetivo analisar as ações e concepções dos professores em relação à prática ambiental proposta nos projetos escolares. Buscou-se analisar o contexto teórico-metodológico dos projetos de Educação Ambiental desenvolvidos nas escolas envolvidas na pesquisa, traçando um paralelo com as finalidades, objetivos e princípios da Educação Ambiental apontados nos documentos produzidos nos diversos encontros e debates nacionais e internacionais.
\end{abstract}

\section{Palavras-chave:}

Educação Ambiental, projetos, cidadania.

\begin{abstract}
Environmental issues have been a common place in the educational discussions, being formal or informal and, the environmental education has been supported as one of the capable means to generate reflections and actions that lead to new postures in front of the social-environmental reality. Urged to discover how the teachers' actions are supported in relation to their environmental experience, this research searched for analysing the projects of environmental education developed in the public schools, located in Colombo-PR. The main objective of this research was to analyse the teachers' actions and ideas about the environmental experience proposed on the school projects. This research tried to analyse the theoretical-methodological context of the environmental educational projects developed in the schools involved on this research, featuring a parallel with the goals, objectives and principles of the environmental education pointed in the documents produced on several national and international meetings and discussions.
\end{abstract}

\section{Key-words:}

Environmental education, projects, citizenship.

${ }^{1}$ Técnica pedagógica da Secretaria de Estado da Educação do Paraná - Mestre em Geografia - UFPR 


\section{INTRODUÇÃO}

A Educação Ambiental, que surgiu como expressão de que na Terra explorada se esgotam os recursos naturais, alerta para que haja uma preocupação com as questões ambientais. Surge, com isso, a urgente necessidade de passar a tratar os conteúdos ambientais sob o enfoque interdisciplinar dada à complexidade do meio. A interdisciplinaridade traz novas linguagens para a Educação Ambiental, na procura de não se deter no conhecimento compartimentado, mas se volta para a apreensão do conhecimento total.

Os diversos encontros e discussões a respeito da Educação Ambiental no Brasil e no mundo apontam para o desenvolvimento de uma Educação ambiental que busque a compreensão integrada do meio ambiente, em suas múltiplas e complexas relações, envolvendo aspectos ecológicos, psicológicos, legais, políticos, econômicos, científicos, culturais e éticos.

Em nível nacional, no ensino formal, as discussões ambientais passam a permear os conteúdos curriculares, e várias escolas encontram nos projetos educativos um dos caminhos para trabalhar a Educação Ambiental. No município de Colombo/PR, algumas escolas da rede municipal de ensino vêm desenvolvendo projetos de Educação Ambiental, porém, a maioria desses projetos é realizada sem o embasamento teórico/metodológico necessário e sem um envolvimento maior com a comunidade local no entorno das escolas. Sendo assim, torna-se importante realizar um estudo sobre os projetos de Educação Ambiental já desenvolvidos no município de Colombo, para poder traçar planos de atuação que respondam às necessidades dos professores, das equipes pedagógicas e dos alunos das escolas do município.

Em busca da compreensão deste problema, nos propusemos a averiguar as ações dos professores nos projetos de Educação Ambiental, bem como as suas concepções no que concerne a Educação Ambiental e meio ambiente. Assim optamos por uma pesquisa de campo, com os professores das escolas municipais de Colombo, de $1^{\mathrm{a}}$ a $4^{\mathrm{a}}$ séries, que desenvolveram ou estão desenvolvendo projetos de Educação Ambiental, aos quais foram aplicados questionários no período entre agosto e outubro de 2003. A amostra da pesquisa foi composta de dezoito professores. Dos dados resultaram tabelas, quadros e gráficos posteriormente analisados.

\section{RETROSPECTIVA HISTÓRICA DA EA NO MUNDO E NO BRASIL: FINALIDADES, OBJETIVOS E PRINCÍ- PIOS DA EA}

A ocupação e a exploração da terra chegou a um ponto em que sua capacidade de sustentação dá mostras claras de esgotamento, e as premissas do crescimento econômico devem ser revistas com rapidez, em vista de que a Educação Ambiental quer mudança de mentalidade, de relacionamento do homem com o meio. Para tanto, torna-se fundamental a conscientização ambiental das sociedades de modo geral, sendo que a Educação Ambiental é uma das estratégias para desenvolver a cidadania em prol do meio ambiente.

As primeiras preocupações internacionais com a Educação Ambiental datam das décadas de 60 e 70. Sob o impacto das movimentações dos anos 60 , a Organização das Nações Unidas (ONU) realizou em Estocolmo, capital da Suécia, entre 5 e 16 de junho de 1972, a primeira Conferência das Nações Unidas sobre o Meio Humano, que ficou conhecida como Conferência de Estocolmo. Desta Conferência resultaram iniciativas voltadas à $E A$, que adquiriram importância e vigência internacional e passaram a modificar os programas educacionais, como a criação de um organismo da própria ONU, voltado exclusivamente para a área ambiental, chamado Programa das Nações Unidas para o Meio Ambiente (PNUMA) (CZAPSKI, 1998, p. 29).

Outra iniciativa foi a recomendação da criação do Programa Internacional de Educação Ambiental (PIEA), lançado no Seminário Internacional de Educação Ambiental em Belgrado - 1975, no qual foram formulados os princípios orientadores da EA que aparecem na Carta de Belgrado, um dos documentos mais claros sobre a questão ambiental da época (DIAS, 2000; OLIVEIRA, 2000 , p. 125). Assim, essa Carta recomendou a necessidade de uma nova ética global, que fosse "capaz de promover a erradicação da pobreza, da fome, do analfabetismo, da poluição, da exploração e da dominação humana". Entre os objetivos estabelecidos pela Carta de Belgrado, pode-se destacar o de atitudes: "adquirir valores sociais, um profundo interesse pelo meio ambiente e a vontade de participar ativamente em sua proteção e melhoramento" e o de participação: "desenvolver sentimento de responsabilidade e tomar consciência da urgente necessidade de prestar atenção aos problemas do meio ambiente, para que se adotem medidas adequadas" (MININNI-MEDINA, 2001, p. 23). Fica evidente a necessidade de promover, por meio da Educação Ambiental, mudanças de atitudes em relação ao meio ambiente, e a participação consciente e crítica diante das questões ambientais.

As questões de Educação Ambiental voltaram a ser discutidas em 1977, na Primeira Conferência Intergovernamental sobre Educação Ambiental, em Tbilisi, Geórgia (ex-URSS). Esta conferência constitui um marco histórico importante para o desenvolvimento da EA no mundo, à medida que ela trouxe maior 
precisão, comparado à Carta de Belgrado, sobre "as definições, os objetivos, os princípios e as estratégias para a Educação Ambiental, que até hoje são adotados em todo o mundo" (CZAPSKI, 1998, p. 30; OLIVEIRA, 2000, p. 125). Assim, em Tbilisi foram revisados os principais problemas ambientais e as práticas de educação realizadas até então no sentido de ajudar a resolver esses problemas" (PARDO DÍAZ, 2002, p. 53). Essa revisão ajudou a traçar o perfil de conceitos mais precisos sobre a EA, e as recomendações da Conferência transformaram-se em referência indispensável para todos aqueles envolvidos com a educação.

Em Tbilisi, foram elaboradas 41 recomendações, reunidas no Informe final, que se constituem num verdadeiro plano de ação para a EA no planeta. O documento preconiza as posições do Seminário de Belgrado, amplia o objetivo fundamental da EA de maneira a vislumbrar as interdependências econômicas, políticas e ecológicas, e deixa claro que as atitudes tomadas pelos países podem ter conseqüências internacionais (MININNI-MEDINA, 2001, p. 28-29).

Reconhecendo que todos têm direito à Educação Ambiental e que o conceito de meio ambiente engloba uma série de elementos naturais e sociais que devem ser entendidos na sua totalidade, a Conferência de Tbilisi preconizou a importância de se aplicar um enfoque interdisciplinar na Educação Ambiental, utilizando o conteúdo próprio de cada disciplina curricular, adquirindo assim uma perspectiva global e equilibrada das questões a serem analisadas. Enfatizou também que é necessário analisar as questões ambientais, partindo do ponto de vista local, ampliando-as para uma escala global, de forma que os educandos possam se identificar com as condições ambientais de outras regiões geográficas (DIAS, 2000, p. 26-37)

As recomendações, finalidades, princípios e objetivos de Tbilisi passaram a ser debatidos e implantados nos mais diversos países do mundo na tentativa de se alcançar os resultados esperados na resolução dos problemas ambientais. Porém, a continuidade e o agravamento dos problemas ambientais levaram os coordenadores da Conferência de Tbilisi a organizar, dez anos depois, um congresso que retomasse as políticas de Educação Ambiental propostas em Tbilisi e que elaborasse um plano de atuação para a década de 90 . O congresso foi realizado em Moscou, em 1987, e ficou conhecido como Congresso Internacional de Moscou (PARDO DÍAZ, 2002, p. 54). Nos anos seguintes ocorreram vários encontros com o objetivo de traçar princípios e metas para a implantação da Educação Ambiental nos diversos países, como a Conferência das Nações Unidas sobre Meio Ambiente e Desenvolvimento ou Rio-92, realizada em 1992 no Rio de Janeiro, a Conferência Internacional sobre Meio Ambiente e Sociedade: Educação, Consciência Pública para a Sustentabilidade, entre 8 e 12 de dezembro de 1997 em Tessalônica - na Grécia e a Cúpula Mundial sobre Desenvolvimento Sustentável - Rio +10, em Johannesburg - na África do Sul, em 2002.

No Brasil, a institucionalização do debate ambiental ocorreu um ano após a realização da Conferência de Estocolmo, em 1973, quando foi criada a Secretaria Especial do Meio Ambiente (SEMA) que, entre outras atribuições, visava controlar a poluição e promover a Educação Ambiental formal e não formal. Em 1975, o governo promoveu o Primeiro Encontro Nacional sobre Proteção e Melhoria do Meio Ambiente. Em 1976, a SEMA assinou um convênio com a Fundação Educacional do Distrito Federal e a Universidade de Brasília, com a finalidade de viabilizar recursos para a realização do primeiro curso de extensão para professores do $1^{\circ} \mathrm{Grau}$. O curso tinha como objetivos não apenas treinar professores, mas reformular o currículo das escolas do Distrito Federal, introduzindo a temática ambiental na área das ciências físicas e biológicas, com um enfoque que priorizava o indivíduo e o meio ambiente (DIAS, 2000, p. 109; MININNIMEDINA, 2001, p. 97-98).

Embora o Brasil não tenha participado da Conferência Internacional de Tbilisi, em 1977, um pouco antes desse acontecimento, a SEMA e o Ministério do Interior produziram um documento oficial, Educação Ambiental, e definiram que "o objetivo específico do processo de Educação Ambiental era criar uma interação mais harmônica, positiva e permanente entre o homem e o meio, criado por ele, de um lado, e o que ele não criou, de outro,"e que, para isso, se deveria "considerar o ambiente ecológico em sua totalidade: o político, o econômico, o tecnológico, o social, o legislativo, o cultural e o estético; na educação formal." Informava-se também que não poderia ser mantida "a tradicional fragmentação dos conhecimentos ministrados através de disciplinas escolares consideradas como compartimentos estanques" (CZAPSKI, 1998, p. 39).

A partir de então, foram institucionalizados vários órgãos que tinham por finalidade tratar das causas ambientais. No setor político, no âmbito da educação e do meio ambiente, ocorreram muitas conquistas, como leis ambientais, que estão entre as mais avançadas do mundo. Podemos citar a promulgação da Lei Federal $n^{\circ}$ 6.902/81, que estabelece novas áreas de preservação, a Lei Federal $n^{\circ} 6.938 / 81$ da Política Nacional do Meio Ambiente, primeira lei a instituir a Educação Ambiental como instrumento na busca de soluções de problemas ambientais, devendo ser ofertada 
COLLERE, M. A. O. Educação ambiental: a contribuição dos projetos escolares...

em todos os níveis de ensino. Em 1982, entrou em vigor a Lei 7.044/82, que delegou aos Conselhos de Educação compor a parte diversificada dos currículos das escolas para que se instituísse, orientasse e estimulasse a Educação Ambiental, de forma sistematizada, ao longo de todo o processo formador dos cidadãos (PHILIPPI Jr; PELICIONI; COIMBRA, 2002, p. 181). Em 1987, a aprovação do Parecer 226/87 enfatizou a implantação da Educação Ambiental nas escolas, com um caráter interdisciplinar, de maneira a despertar a população para um posicionamento em relação às questões ambientais (CZAPSKI, 1998, p. 42).

Em 1997, foi realizada a Primeira Conferência Nacional de Educação Ambiental, a I CNEA, em Brasília. O principal objetivo da Conferência era realizar uma avaliação acerca das práticas da educação ambiental no país, ou seja, um diagnóstico da situação da educação ambiental brasileira, e apontando as perspectivas e estratégias para o futuro (DIAS, 2000, p. 180; MININNI-MEDINA, 2001, p. 106).

No ano de 1999, foi aprovada a Lei $n^{\circ}$ 9.795/99, que dispõe sobre a Política Nacional de Educação Ambiental, esta devendo ser entendida como processo por meio do qual o indivíduo e a coletividade constroem valores sociais, conhecimentos, habilidades, atitudes e competências voltados para a conservação do meio ambiente que é bem de uso comum do povo, essencial à sadia qualidade de vida e sua sustentabilidade. E, ainda, que a educação ambiental deve estar presente em todos os níveis e modalidades da educação, em caráter formal e não-formal, possuindo um enfoque humanista, holístico, democrático e participativo, concebendo o meio ambiente na sua totalidade (DIAS, 2000 , p. 201). Nesse sentido, é enfatizada a importância do caráter interdisciplinar, possibilitando a compreensão "integrada do meio ambiente em suas múltiplas e complexas relações, envolvendo aspectos ecológicos, psicológicos, legais políticos, sociais, econômicos, científicos, culturais e éticos (...)" (PHILIPPI Jr.; PELICIONI, 2002, p. 41-42).

\section{O CARÁTER INTERDISCIPLINAR DA EDUCAÇÃO AMBIENTAL NO ENSINO FORMAL}

A interdisciplinaridade já estava presente desde a Carta de Belgrado, sendo reafirmada nas discussões da Conferência de Tblisi, quando foi focalizado que um dos principais objetivos da Educação Ambiental é fazer com que a sociedade compreenda a complexidade do meio ambiente natural e do meio criado pelo homem, resultantes da interação dos aspectos físico-biológicos, econômicos e socioculturais, e que desenvolvam conhecimentos, valores, comportamentos e habilidades práticas que lhes permitam participar como coresponsáveis pela prevenção e solução dos problemas ambientais e pela gestão da qualidade do meio ambiente (PHILIPPI Jr; PELICIONI; COIMBRA, 2002, p. 180).

Mininni-Medina (2001, p. 39), ao discutir a importância da interdisciplinaridade da Educação Ambiental, afirma que esta "põe ênfase no desenvolvimento de valores e comportamentos diferentes, na relação dos homens com o meio ambiente, defende a necessidade de um conhecimento integrado da realidade e procedimentos baseados na investigação dos problemas ambientais, utilizando estratégias interdisciplinares".

Tendo como ponto de partida o oferecimento de subsídios para que cada escola elabore e adapte seu currículo de acordo com a realidade local e à faixa etária dos alunos, o Ministério da Educação e do Desporto, publicou os Parâmetros Curriculares Nacionais (PCNs), que trazem orientações para o ensino dos Temas Transversais que devem permear todas as disciplinas. Desta forma, a escola estaria cumprindo seu papel constitucional de fortalecimento da cidadania (PHILIPPI Jr; PELICIONI; COIMBRA, 2002, p. 182).

De acordo com os PCNs, todas as disciplinas devem abordar os Temas Transversais que são divididos em Ética, Pluralidade Cultural, Meio Ambiente, Saúde e Orientação Sexual, comuns para todo o Ensino Fundamental. A transversalidade é proposta nos PCNs como tema que deve ser tratado de maneira articulada com as matérias do currículo escolar. Sendo assim, deve estar presente em todas as áreas, de forma a estabelecer uma relação entre os conteúdos clássicos e as questões da atualidade. Dessa forma, os Temas Transversais, "não pretendem incluir novos conteúdos nas disciplinas, mas alertar para temas de importância social" (CORDIOLLI, 1999, p. 8-9).

Oliveira (2000, p. 93-94), sugere alguns passos para viabilizar a Educação Ambiental como trabalho interdisciplinar, tais como: a "formulação de um projeto pedagógico para a escola que reflita o espaço sociopolítico-econômico-cultural em que ela se insere"; levantamento de "situações-problema relevantes, referentes à realidade em que a escola está inserida, a partir das quais busca-se a formulação de temas para estudo, análise e reflexão" e a estruturação de "uma matriz de conteúdos intercruzando conteúdos/disciplinas X situações -problema/temas". Além disso, é necessário que sejam realizados seminários, encontros, debates entre os professores, para compatibilizar as abordagens dos conteúdos próprios de suas disciplinas com as situações-problema, buscando, assim, a convergência de ações. 
Uma das melhores formas de conseguir atingir a interdisciplinaridade no processo educativo é o desenvolvimento do ensino por meio de projetos, pois eles possibilitam variadas atividades de reflexão dos conteúdos escolares em interação com as várias áreas do conhecimento. Pois, o trabalho com projetos "supera as práticas de ensino habituais pela criação de novos instrumentos pedagógicos que envolvam mais a participação dos alunos", cuja realização "favorece a interdisciplinaridade de conteúdos pela realização de tarefas e atividades voltadas para a aprendizagem participativa" (MARTINS, 2002, p. 18).

O projeto necessita ter um tema central, uma situação real (problema). Para isso, o professor, como intermediador, precisa criar uma situação em que os alunos utilizem suas experiências, despertando assim a necessidade de adquirir novos conhecimentos. A exploração e o tratamento de um problema que tem relação direta com a realidade social estimula os alunos a tratar um mesmo problema a partir de pontos de vista diferentes "ultrapassando os limites tradicionais entre as disciplinas" (VILA NOVA, 1999, p. 34). O projeto, pois, é importante porque possibilita a pesquisa que, por sua vez, impulsiona a criatividade do aluno para que ele não receba passivamente tudo pronto, submetendose a todas as informações que Ihe são passadas como produto acabado. Ele passa a agir e a ser sujeito de seu próprio conhecimento.

Entretanto, é preciso estar atento e preparado para a possibilidade tanto de sucesso como de insucesso em relação ao projeto, pois no decorrer de seu desenvolvimento aparecerão aspectos às vezes não considerados na proposta inicial (SEGURA, 1999, p. 51).

Outro fator a ser considerado no trabalho com projetos é que, embora ele represente uma busca de ações individuais e coletivas, de autonomia, de criatividade e da inovação, o projeto corre o risco de se tornar um ativismo alienante ao invés de algo emancipador, quando é padronizado ou envolto em problemas individuais ou até mesmo coletivos (SEGURA, 1999 p. 52).

Martins (2002, p. 60-63), ao discutir os problemas enfrentados nos projetos de EA, aponta como primeira deficiência "a falta da seqüência sensibilização- capacitação-gerenciamento nos processos de capacitação e na execução dos projetos de Educação Ambiental no país", sendo que a falta de pessoas qualificadas para a execução dos projetos é a segunda deficiência, observada na hora da elaboração, da execução, do acompanhamento e avaliação dos projetos. Então, a criatividade dá lugar ao oportunismo e à improvisação e a educação ambiental se torna algo que pode receber a opinião de muitos que podem não estar vivenciando-a na prática. É importante que o professor tenha bem claro o que é um projeto, como ele deve ser pensado e desenvolvido, para que ele não seja tratado como um modismo, uma mera atividade que aborda uma temática qualquer. Desse modo, um projeto bem planejado e executado proporciona o reconhecimento por parte dos alunos de que a realidade social é produzida por pessoas e pela sua troca criativa de saberes. É alicerçado nesses referenciais teóricos, que buscam discutir os princípios e objetivos da Educação Ambiental, tendo a interdisciplinaridade desenvolvida por meio dos projetos escolares de Educação Ambiental como um dos caminhos para a formação do aluno cidadão que, então, avaliaremos os projetos de Educação Ambiental desenvolvidos nas séries iniciais do ensino fundamental da rede pública municipal de Colombo/PR.

\section{EDUCAÇÃO AMBIENTAL E UNIVERSO ESCOLAR: UMA LEITURA À LUZ DAS PRÁTICAS}

Os dados levantados com os sujeitos da pesquisa (professores de $1^{\mathrm{a}}$ a $4^{\mathrm{a}}$ séries do ensino fundamental das escolas públicas municipais de Colombo, envolvidos em projetos de Educação Ambiental) procuraram contribuir para a resolução das questões e dos objetivos propostos na pesquisa. Para tanto, serão inicialmente trabalhados os dados da Parte I do questionário, que dizem respeito à formação dos professores. Essa parte se constitui como fundamental, afinal a formação e capacitação docente são elementos básicos quando se busca entender suas atitudes e ações no processo de ensino e aprendizagem.

A Tabela 1 faz referência à formação dos professores:

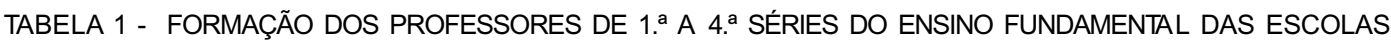
MUNICIPAIS DA CIDADE DE COLOMBO RARTICIPANTES DA PESQUISA

\begin{tabular}{ll|l}
\hline Formaçấo & F & $\%$ \\
\hline a. Apenas o magisterio & 2 & 11 \\
b. Magistério e superior incompleto & 5 & 28 \\
c. Magistério e superior completo & 5 & 28 \\
d. Magislério, Superior Complelò & 6 & 33 \\
Pós-graduaçāo (especializaçāo) & & \\
Total Geral & 18 & 100 \\
\hline
\end{tabular}


COLLERE, M. A. O. Educação ambiental: a contribuição dos projetos escolares...

A Tabela 1 mostra que, dos dezoito professores, apenas dois, ou seja, $11 \%$ não cursaram o ensino superior, possuindo apenas o magistério. Esses dados demonstram que a maioria dos professores está buscando o aprimoramento na sua profissão. Tal situação influencia diretamente na qualidade do ensino de forma geral, repercutindo também no processo escolar, pois esta abordagem educacional exige uma visão mais profunda da educação.

Quando questionados acerca dos cursos de pósgraduação, verificou-se que seis professores cursaram ou estão cursando pós-graduação em nível de especialização, porém, nenhum deles fez pós na área de Educação Ambiental. Este fato impacta diretamente sobre o objeto e o fazer Educação Ambiental nas séries iniciais; afinal as questões ambientais são complexas e exigem um conhecimento referenciado da parte do educador para evitar generalizações e equívocos ambientais na formação cidadã do educando, isto é, uma formação crítica das relações sociedade-natureza. Esse fato torna-se mais preocupante ao verificar os dados referentes à participação dos docentes em atividades de Educação Ambiental, como pode-se verificar na Tabela 2:

TABELA 2 - PARTICIPAÇÃO EM ATIVIDADES DE CAPACITAÇÃO EM EDUCAÇÃO AMBIENTAL

\begin{tabular}{lc|c}
\hline Atividades & F & $\%$ \\
\hline a. Näo participaram & 10 & 53 \\
b. Palestras & 5 & 26 \\
c. Cursos & 3 & 16 \\
d. Projelos & 1 & 5 \\
Pós-graduaçäo (especializaçäo) & & \\
Tolal Geral* & 18 & 100 \\
\hline
\end{tabular}

(") Este total corresponde ao número de elementos de conteúdos listados pelos professores.

Os dados referentes à capacitação dos professores em Educação Ambiental mostram que um pouco mais da metade, ou $53 \%$, nunca participou de atividades de capacitação relacionadas a essa área. Este fato demonstra que muitos professores não estão tendo acesso a encontros e programas de formação em Educação Ambiental, ou seja, não estão sendo cumpridas as recomendações dadas desde Estocolmo (1972) até a Conferência de Tessalônica (1997), no sentido de promover a qualificação dos educadores em relação à EA (cursos, encontros, trocas de experiências, etc.) para aprofundar os debates e socializar as informações e experiências (DIAS, 2000, p. 58). Nesse sentido, (MINNINI MEDINA, 2001, p. 84), destaca a importância da formação dos docentes, em termos de que "os programas de formação de professores em educação ambiental para o desenvolvimento sustentável são prioritários e deve-se dar possibilidades para a participação e criação de práticas pedagógicas inovadoras".

A Prefeitura Municipal de Colombo, por meio da parceria entre a Secretaria Municipal de Educação e do Departamento de Meio Ambiente iniciou em 2003 o "Programa de Educação Ambiental", com o objetivo de formar grupos multiplicadores nas escolas. Foram realizados quatro encontros durante o ano de 2003, nos quais foram discutidos temas como dificuldades encontradas nas escolas para o desenvolvimento de atividades de Educação Ambiental, documentos e encontros internacionais relativos à Educação Ambiental, Agenda 21, trabalho com projetos, entre outros.

No entanto, estes encontros não foram direcionados aos professores da rede, mas sim aos coordenadores das escolas. Diante da dificuldade para tirar o professor da sala de aula, visto que a rede não possui professores substitutos, o repasse das informações que os coordenadores recebem nos momentos de formação continuada raramente chega até o professor. Considerando tais fatos, pode-se dizer que, em virtude da falta de formação dos docentes, eles têm dificuldades em tratar o tema meio ambiente em suas aulas. É o poder público e sua trajetória burocrática e desvinculada da realidade, que impede uma formação cidadã necessária para o desenvolvimento de uma sociedade democrática.

Desta forma, retomamos as palavras de Oliveira (2000, p. 93), discutidas nesta pesquisa, que afirma ser necessário vencer três dificuldades para a implantação da Educação Ambiental: a busca de novas metodologias para trabalhar a interdisciplinaridade, a rigidez curricular em relação à grade horária, conteúdos, avaliação e outros e a sensibilização do corpo docente para que busquem novas práticas para enfrentar as dificuldades e desafios que exigem trabalho e criatividade. No caso específico, as três dificuldades são "engessadas" pela visão pequena do poder público. E, tais contradições no 
meio escolar, vão com certeza repercutir no desenvolvimento qualitativo dos projetos de Educação Ambiental, bem como na concepção dos docentes em relação ao meio ambiente e Educação Ambiental, como verifica-se na Tabela 3 .

TABELA 3 - ENTENDIMENTO DE MEIO AMBIENTE

\begin{tabular}{l|c}
\hline Rcspostas & $\%$ \\
\hline a. Elcmontos naturais & 33,3 \\
b. Espaço de vida & 33,3 \\
c. Imteraçāo entre sociedade e matureza & 12,5 \\
d. Lugar modificado pelo homem & 4,2 \\
e. Lugar idealizado & 4,2 \\
f. NP & 8,3 \\
g. NR & 4,2 \\
Total & 100 \\
\hline
\end{tabular}

A pergunta - Qual é o seu entendimento de meio ambiente?- suscitou várias respostas. A maior parte, $33,3 \%$ delas, referiu-se a percepções ligadas à natureza, tanto do meio biótico quanto abiótico, apresentando, portanto, o que se chama de "visão naturalista" do meio ambiente, sem estabelecer relações com os aspectos sociais, políticos, econômicos e culturais que caracterizam o meio ambiente na sua totalidade. A percepção de meio ambiente enquanto espaço de vida apareceu também em 33,3\% das respostas. Assim como na questão anterior, referente ao meio ambiente como elementos naturais, as respostas aqui apresentadas demonstram que os professores não conseguem compreender o meio ambiente na sua totalidade e complexidade.

Apenas três professores apresentaram respostas nas quais demonstram compreender o meio ambiente, não apenas como elementos naturais, mas também como resultado da cultura, política, trabalho, entre outros. Dentre as três respostas, um dos professores evidenciou a relação homem-natureza e os aspectos que resultam dessa relação. A seguir, a resposta do referido professor:

Relação homem-natureza, traz a discussão a respeito da relação entre os problemas ambientais e fatores econômicos, políticos, sociais e históricos (E. M. John Kennedy).

Esta concepção está de acordo com a Conferência de Tbilisi, onde, segundo a análise de Pardo Díaz (2002, p. 53), o meio ambiente "abrange, ao mesmo tempo os aspectos naturais e aqueles decorrentes das atividades humanas". Porém, é importante que o professor compreenda como ocorre a relação e a interdependência entre os elementos naturais, assim como entre a sociedade (aspectos econômicos, sociais, políticos, culturais, históricos, entre outros) e a natureza.

Um professor apresentou o entendimento de meio ambiente como um lugar idealizado, que precisa ser cuidado. A resposta corresponde, de certa forma, a uma visão naturalista de como o meio ambiente é concebido, distante da realidade que se coloca, com todas as questões ambientais da atualidade que pedem reflexões e tomada de atitudes. Abaixo, a resposta para ilustrar essa questão:

Eu entendo que o meio ambiente é muito importante. Um tesouro que o Criador nos oferece. Devemos cuidar do nosso planeta Terra (E. M. Carlos Fontoura FALAVINHA).

No que concerne ao entendimento dos professores a respeito de Educação Ambiental, verificável na Tabela 4, percebe-se uma estreita relação com a concepção de meio ambiente.

TABELA 4 - ENTENDIMENTO DE EDUCAÇÃO AMBIENTAL

\begin{tabular}{l|c}
\hline Respostas & $\%$ \\
a. Desenvolvinento de atitudes de & 57 \\
preservaça/conservacäo/melhoria da & \\
natureza e do anbiente de vida & \\
b. Transmissäo de conhecimento & 16 \\
c. Desenvolvimento da cidadania & 11 \\
d. NR & 16 \\
Total & 100 \\
\hline
\end{tabular}

Pode-se verificar na Tabela 4 que mais da metade das respostas dos professores, $57 \%$, entendem Educação Ambiental como práticas que levam os alunos ao desenvolvimento de atitudes de preservação, conservação e melhoria do meio ambiente. Dentre estes $57 \%$, três respostas, ou 16\%, acreditam que a Educação Ambiental deve levar ao desenvolvimento de atitudes em relação à natureza. As respostas dos três professores demonstram que, para eles, Educação Ambiental é um trabalho que tem por objetivo conscientizar as pessoas em relação às atitudes de preservação, conservação e melhoria dos elementos naturais do meio ambiente, sem fazer relação com os demais aspectos. Novamente pode-se afirmar que falta a esses professores oportunidade de tomarem conhecimento da amplitude e complexidade que envolvem as questões ambientais, assim como dos conceitos de preservação e conservação.

Dentre os professores que responderam que a Educação Ambiental visa o desenvolvimento de atitudes em relação ao ambiente de vida, é possível perceber que eles reconhecem que o homem exerce influência 
COLLERE, M. A. O. Educação ambiental: a contribuição dos projetos escolares...

sobre o meio ambiente, mas não deixam claro essa relação homem-natureza, apenas que é necessário cuidar, preservar e/ou conservar e melhorar o meio em que vivem.

$\mathrm{Na}$ categoria de entendimento da Educação Ambiental como transmissão de conhecimento, os professores se referiram a este como um caminho para a conscientização em prol da conservação do meio.

A Educação Ambiental, como desenvolvimento da cidadania, apareceu em apenas duas respostas, como podemos verificar a seguir:

Quando mudamos nosso comportamento em relação a economia, distribuição, limpeza, etc. (E.M. Jucondo D'Agostin);

Em termos de educação essa perspectiva contribui para evidenciar a necessidade de um trabalho vinculado aos princípios da dignidade do ser humano (E.M. Parque Monte Castelo).

Embora a palavra cidadania não tenha aparecido de forma explícita nas respostas, entende-se que quando o professor visa mudar o comportamento em relação aos aspectos econômicos e sociais, buscando a dignidade do ser humano, está desenvolvendo a cidadania nos seus alunos e naqueles que os projetos atingem.

De acordo com Guimarães (1995, p. 26), a conscientização, a transmissão de conhecimentos, o desenvolvimento de atitudes e valores fazem parte da Educação Ambiental, mas é preciso também que esta desperte nos cidadãos a vontade, capaz de fazê-los atuar, em nível individual e coletivo, na resolução dos problemas atuais e futuros do meio ambiente e um trabalho orientado por uma perspectiva interdisciplinar é fator fundamental para atingir esses objetivos, levandoos a compreender a complexidade dos problemas ambientais e a multiplicidade dos elementos que o constituem.

As respostas apresentadas nas Tabelas 3 e 4 demonstram que a maioria dos professores não compreendem o meio ambiente no seu caráter holístico e integrador, pelas dificuldades apresentadas anteriormente, decorrentes da falta de cursos de capacitação na área de Educação Ambiental aos professores e da falta de textos relativos à Educação Ambiental que permitam ao docente tomar conhecimento das discussões que estão acontecendo em nível nacional e mundial.

Enquanto não for propiciado ao professor participar mais ativamente dessas discussões, certamente, continuarão enfrentando dificuldades para compreender que o meio ambiente abrange mais do que os elementos naturais ou o espaço de vida dos seres vivos. É necessário que se compreenda a integração e a interdependência e interlocuções dos elementos naturais, sociais, políticos, econômicos, tecnológicos, históricos e culturais que integram e dinamizam o meio ambiente.

Fica evidente que uma das dificuldades que o professor enfrenta em relação à sua formação continuada direcionada à Educação Ambiental é a rigidez do sistema educacional no que concerne, principalmente, à oportunidade de participar dos eventos que acontecem, visto que não pode deixar a escola, pois não há professores para substituí-lo na sua ausência. No entanto, o professor sente a necessidade de formação na área de Educação ambiental, bem como de material específico para trabalhar. Esses dados são demonstrados na Tabela 5:

TABELA 5 - O QUE FALTA NA REDE PARA ENRIQUECER OS PROJET OS DE EDUCAÇÃO AMBIENTAL?

\begin{tabular}{l|c}
\hline Respostas & $\%$ \\
\hline a. cursos & 36 \\
b. material didático & 28 \\
c. transporte & 12 \\
d. compromisso das autoridades & 8 \\
e. adaptar o currículo escolar & 4 \\
f. NP & 8 \\
g. NR & 4 \\
Total & 100 \\
\hline
\end{tabular}

A Tabela 5 reafirma a necessidade que os professores têm de participar de cursos de Educação Ambiental, com $36 \%$ das respostas, e também de acesso a material didático como livros, vídeos e outras fontes bibliográficas, que apareceu em $28 \%$ das respostas apresentadas. Os professores, em $12 \%$ das respostas, alegaram que falta transporte para deslocar os alunos para trabalhos de campo. Essa também foi uma das reclamações dos coordenadores das escolas que participaram, durante o ano de 2003, do Programa de Educação Ambiental realizado pela Prefeitura Municipal de Colombo.

Essa queixa, de certa forma, vai contra um dos principais objetivos da Educação Ambiental, que é analisar as questões ambientais, partindo do ponto de vista local. Isto é, o professor deve realizar primeiramente o trabalho conhecendo a realidade em que o aluno está inserido, e para isso não há necessidade de transporte.

É evidente que a visita a determinados locais que estejam relacionados aos temas trabalhados nos projetos tais como: usinas de reciclagem, estações de tratamento de água e esgoto, entre outros, enriquece o 
projeto. No entanto, a falta de transporte para esses trabalhos não deve ser fator desestimulante para a realização dos projetos de Educação Ambiental, afinal vencer desafios e dificuldades, usando de criatividade, é um dos papéis da educação e do educador.

Em 8\% do total das respostas, os professores relataram que falta mais apoio e envolvimento das autoridades locais para que os projetos possam atingir seus objetivos. Desta forma, os projetos de Educação Ambiental devem suscitar ações que propiciem o envolvimento das autoridades locais, bem como a cobrança das mesmas, quando da não participação.

\section{CONSIDERAÇÕES FINAIS}

Constatou-se no decorrer deste trabalho que, em conseqüência da falta de formação em Educação Ambiental, os professores encontram dificuldades em desenvolver seus projetos de forma a levar seus alunos e comunidade local a um trabalho reflexivo que resulte em efetiva mudança de atitude em relação ao meio em que vive. Sendo assim, fica evidente que em sua formação e prática educacional, os professores:

a) devido à falta de oportunidade para aprofundamento a respeito da Educação Ambiental, desconhecem leituras especializadas na temática, pois apontam como maior fonte de pesquisa oficial apenas os PCNs;

b) não são beneficiados pelos propósitos dos organismos internacionais e nacionais, que muito falam sobre o assunto, mas não conseguem estabelecer estratégias que façam chegar a Educação Ambiental à prática do cotidiano das escolas;

c) encontram dificuldades em inovar suas práticas porque suas iniciativas emperram no próprio sistema educacional, pois o currículo não permite que eles saiam do tradicional e criem formas específicas de trabalhar o tema;

d) não conseguem desenvolver os projetos de Educação Ambiental de maneira interdisciplinar, mesmo trabalhando em conjunto. Mesmo assim, as escolas que desenvolvem projetos que incluem todas as séries e a comunidade obtêm melhores resultados do que aquelas que trabalham isoladamente;

e) não recebem as informações dos eventos de Educação Ambiental organizados pela Secretaria de Educação e de Meio Ambiente municipais, dos quais os coordenadores participam com o compromisso de repassar aos professores.

Diante dos fatos discutidos anteriormente são apontadas, a seguir, algumas considerações indicativas.

- É imprescindível que os órgãos competentes invistam na capacitação do professor na área de Educação Ambiental por meio de:

1. formação continuada: propiciando grupos de estudo, seminários, cursos e atividades práticas;

2. acesso a material especializado na temática ambiental (livros, textos, documentos, vídeos, entre outros);

3. momentos de integração, nos quais os professores possam estar compartilhando as experiências desenvolvidas nas escolas;

4. maior cooperação da Secretaria Municipal de Educação no sentido de disponibilizar oportunidades para que os professores da rede possam participar dos eventos direcionados à Educação Ambiental;

5. maior integração entre órgãos públicos, principalmente entre a Secretaria Municipal de Educação e a Secretaria de Estado da Educação, e destes com outros organismos públicos e privados ligados à temática, para estabelecerem parcerias que visem melhorar a qualidade da formação dos professores para o trabalho de Educação Ambiental.

Sem essa formação torna-se difícil para os professores vencer as três dificuldades normalmente encontradas na implantação da Educação Ambiental: a busca de novas metodologias para trabalhar de maneira interdisciplinar; a rigidez curricular em relação à grade horária, aos conteúdos e à avaliação; e a sensibilização do corpo docente para que busque novas práticas com a finalidade de enfrentar as dificuldades e desafios que exigem trabalho e criatividade. 
COLLERE, M. A. O. Educação ambiental: a contribuição dos projetos escolares...

\section{REFERÊNCIAS}

CORDIOLLI, M. Para entender os PCN's: os temas transversais. Curitiba: Módulo, 1999.

CZAPSKI, S. A implantação da educação ambiental no Brasil. Brasília: MEC, 1998.

DIAS, G. F. Educação ambiental: princípios e práticas. São Paulo: Gaia, 2000.

GUIMARÃES, M. A dimensão ambiental na educação. São Paulo: Papirus, 1995.

MARTINS, J. S. O trabalho com projetos de pesquisa: do ensino fundamental ao ensino médio. Campinas, São Paulo: Papirus, 2002.

MININNI-MEDINA, N. Antecedentes históricos: conferências internacionais sobre educação ambiental. In: EDUCAÇÃO AMBIENTAL: curso básico a distância: questões ambientais, conceitos, história, problemas e alternativas. 2. ed. ampl. Brasília: MMA, 2001
OLIVEIRA, E. M. Educação ambiental: uma possível abordagem. Brasília: Ibama, 2000.

PARDO DÍAZ, A. Educação ambiental como projeto. 2. ed. Porto Alegre: Artmed, 2002.

PHILIPPI Jr., A.; PELICIONI, M. C. F. Educação ambiental: desenvolvimento de cursos e projetos. São Paulo: Signus, 2002.

;; COIMBRA, J. Á. A. Visão de Interdisciplinaridade na Educação Ambiental. In: PHILIPPI Jr., A.; PELICIONI, M. C. F. Educação ambiental: desenvolvimento de cursos e projetos. São Paulo: Signus, 2002.

SEGURA, D. S. B. Venturas e desventuras da educação ambiental na escola pública: um estudo de experiências na zona leste do município de São Paulo. São Paulo, 1999. Dissertação (Mestrado em Educação) - Universidade de São Paulo.

VILA NOVA, E. Educar para o ambiente. 2. ed. Lisboa: Texto, 1999. 